\title{
Energy Reduction for a Dual Circuit Cooling Water System Using Advanced Regulatory Control ${ }^{\text {th }}$
}

\author{
C.J. Muller ${ }^{\mathrm{a}, \mathrm{b}}$, I.K. Craig,** \\ ${ }^{a}$ Sasol, Sasolburg, South Africa. \\ ${ }^{b}$ Department of Electrical, Electronic, and Computer Engineering, University of Pretoria, \\ Pretoria, South Africa.
}

\begin{abstract}
Various process utilities are used in the petrochemical industry as auxiliary variables to facilitate the addition/removal of energy to/from the process, power process equipment and inhibit unwanted reaction. Optimisation activities usually focus on the process itself or on the utility consumption though the generation and distribution of these utilities are often overlooked in this regard. Many utilities are prepared or generated far from the process plant and have to be transported or transmitted, giving rise to more losses and potential inefficiencies. To illustrate the potential benefit of utility optimisation, this paper explores the control of a dual circuit cooling water system with focus on energy reduction subject process constraints. This is accomplished through the development of an advanced regulatory control (ARC) and switching strategy which does not require the development of a system model, only rudimentary knowledge of the behaviour of the process and system constraints. The novelty of this manuscript lies in the fact that it demonstrates that significant energy savings can be obtained by applying ARC to a process utility containing both discrete and continuous dynamics. Furthermore, the proposed ARC strategy does not require a plant model, uses only existing plant equipment, and can
\end{abstract}

\footnotetext{
This work is based on research partly supported by the National Research Foundation of South Africa (Grant No. 90533).

*Corresponding author. Tel.: +27 124202172 .

Email addresses: nelis.muller@sasol.com, nelismuller@gmail.com (C.J. Muller), ian.craig@up.ac.za (I.K. Craig)
} 
be implemented on control system hardware commonly used in industry. The simulation results indicate energy saving potential in the region of $30 \%$ on the system under investigation.

Keywords: Utility, optimisation, control, energy

\section{Introduction}

Process utilities are used extensively in the operation of any petrochemical plant and may include steam, electricity, compressed air, cooling water, fuel gas and inerts such as nitrogen. A substantial portion of the fixed cost associated with plant operation is attributed to utilities and therefore it is common practice to optimise on the plant's consumption of these utilities $[1,2]$. The generation and distribution of these utilities also require energy yet these aspects do not get the deserved attention while studies have shown that the energy losses are in many cases substantial $[3,4]$. Furthermore, better control can reduce the variability of the utility which could improve plant stability and reduce the need to run large buffer capacities.

The optimisation of utilities can be very beneficial but usually requires additional capital expenditure which is a main deterrent for many energy efficiency improvement initiatives $[5,6,7]$. Furthermore, with steep increases in energy costs, a solution which is currently deemed infeasible could become feasible in the near future although a re-evaluation of the opportunity will seldom be done which results in missed optimisation opportunities.

In several recent publications, model based control techniques such as optimal control and model predictive control (MPC) are used for energy optimisation which require system models to be developed and an optimisation algorithms capable of solving the optimisation problems (usually as a real-time requirement).

In [5] and [6], a fuel gas blending system is optimised using model predictive control and real-time optimisation. In [8], optimal control and model predictive control strategies are used for optimising power flows between the grid and a 
photovoltaic-battery system using time-of-use tariffs and sell back rates. In [9], occupancy and weather forecast data is used with an MPC scheme to minimise the energy consumption of a building temperature control system taking into account specified comfort requirements. In [10], an optimal control strategy is used to optimise water flow rates in a ground source heat pump system. In [11], [13] and [14], optimal control is used to optimise energy consumption and costs for belt conveyor systems. In [12], MPC is used with time-of-use cost data to optimise the energy cost for a run-of-mine ore milling circuit. In [15], [16] and [18], optimal control and/or MPC techniques are used to optimise energy costs in a water pumping systems.

In industrial applications, these control techniques typically imply additional software licence fees and computer hardware (or even the installation of additional plant equipment such as variable speed drives).

This paper demonstrates a novel way of obtaining significant energy savings on a process utility containing both discrete and continuous dynamics by applying advanced regulatory control (ARC) and switching logic. Furthermore, the proposed ARC and switching strategy does not require the development of a plant model, uses only existing plant equipment, and can be implemented on control system hardware commonly used in industry.

The developed solution is applied to a dual circuit cooling water system in a simulation study and compared to the unoptimised base case to illustrate the potential benefit of utility optimisation. Specific focus is on the reduction of electricity consumed by the system while still taking the process constraints into account.

The cooling water system is an example of a hybrid system where both continuous and discrete handles are present in the same system which complicates the formulation of control and optimisation strategies [19, 20,21]. Typically, the discrete and continuous portions are treated separately and several studies have been performed recently concerning the former $[11,15,16]$. Therefore, this strategy is particularly useful for these system where the bulk of the possible benefit may be realised without the use of the more advanced control techniques. 
A systematic approach is also described to allow the control and switching techniques used in this paper to be extended to other discrete or hybrid systems.

The paper is structured as follows: In Section 2, a brief process description of the cooling water system is given where-after the process model is discussed in Section 3. In Section 4, the control and switching algorithms are described and the simulation schemes for the base case and the ARC are presented. Thereafter, the simulation results are analysed and discussed in Section 5 followed by the concluding statements in Section 6 .

\section{Process Description}

An example of a utility process is that of a dual circuit cooling water system as shown in Figure 1. The tempered water (TW) circuit is a closed treated water loop that runs through the plant heat exchanger network where it absorbs energy from the plant. The tempered water is impelled by a bank of parallel pumps. It transfers the collected energy to the second circuit, the cooling water (CW) circuit, via a bank of plate heat exchangers. The cooling water circuit is also driven by its own bank of parallel pumps. The energy is then expelled from the cooling water through the cooling towers (CTs) where the main mechanism for cooling is the partial evaporation of a portion of the cooling water as it comes into contact with the unsaturated air stream that is induced by the cooling tower fans [22, 23].

This process is an example of a hybrid system where a combination of continuous and discrete process input variables are present. The continuous inputs are for example the valve openings of the control valves whereas the discrete inputs are the pump and fan running signals. In cases where the discrete and the continuous portions can reasonably be treated separately, a discrete optimiser may be used for the discrete variables whereas an independent continuous optimiser may be used for the continuous part. In cases where these layers are integrated to a great extent (as is the case for the cooling water system), it is desirable to combine the continuous and discrete aspects into a single control and 
Table 1: Abbreviations.

\begin{tabular}{|c|l|}
\hline \multicolumn{2}{|c|}{ Table 1: Abbreviations. } \\
\hline ARC & Description \\
CT & Cooling Tower \\
CV & Controlled Variable \\
CW & Cooling Water \\
DCS & Distributed Control System \\
DV & Disturbance Variable \\
E & Exchanger \\
MV & Manipulated Variable \\
P & Pump \\
PIC & Pressure Indicator Controller \\
PLC & Programmable Logic Controller \\
PV & Pressure Valve \\
TIC & Temperature Indicator Controller \\
TV & Temperature Valve \\
TW & Tempered Water \\
\hline
\end{tabular}




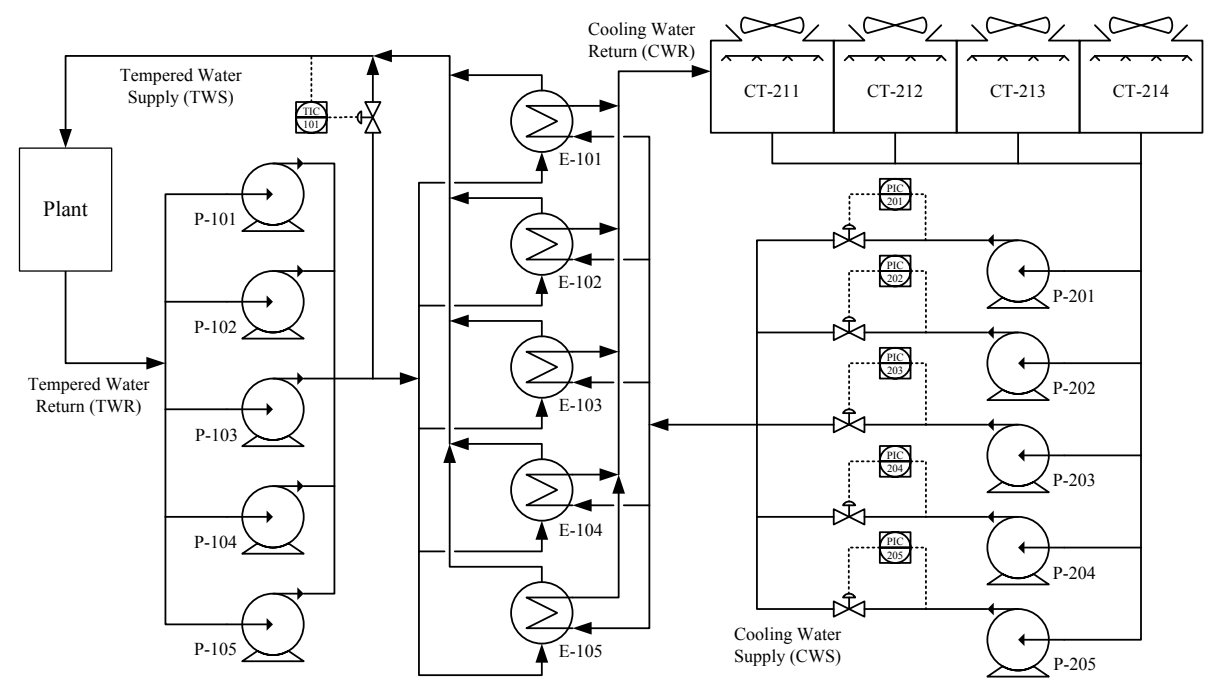

Figure 1: Dual circuit induced draft counter-flow cooling water system [21]. Refer to Table 1 for the abbreviations.

optimisation solution which complicates the optimisation problem [19, 20, 24].

\section{Process Model}

The model developed by Muller and Craig [21] was extended to include the valves on the discharges of the cooling water pumps (as indicated in Figure 1) with the simplifying assumption that the same value is written to all valves or which the pumps are running. The model is used as a representation of the actual process in the simulation study that follows and is not required for the formulation of the control and switching solution discussed in Section 4. The model was re-verified using the same verification data used in [21] and the parameters updated by performing the parameter estimation exercise described $\mathrm{n}[21]$.

The process inputs are

- the temperature control valve (TV) opening $\left(O P_{T V}\right)$ (which has a linear characteristic), 
- the cooling water pump discharge pressure control valve (PV) openings $\left(O P_{P V}\right)$ (which have equal percentage characteristics - the simplifying assumption is that the same valve opening is sent to the discharge valves of all the running cooling water pumps), and

- the tempered water and cooling water pump and cooling tower fan running signals, $u_{i}^{T W}(t) \in\{0,1\}, u_{j}^{C W}(t) \in\{0,1\}$, and $u_{k}^{C T}(t) \in\{0,1\}$,

with $i=1 \ldots n_{T W}, j=1 \ldots n_{C W}$, and $k=1 \ldots n_{C T}$ where $n_{T W}, n_{C W}$ and $n_{C T}$ are the numbers of tempered water pumps, cooling water pumps and cooling tower fans. The binary running signals are grouped together into discrete integer signals representing the number of pumps or fans running to give $U_{T W}(t)=\sum_{i=1}^{n_{T W}} u_{i}^{T W}(t), U_{C W}(t)=\sum_{j=1}^{n_{C W}} u_{j}^{C W}(t)$ and $U_{C T}(t)=\sum_{k=1}^{n_{C T}} u_{k}^{C T}(t)$.

The process disturbances are

- the plant duty, $Q_{P}(t)(\mathrm{MJ} / \mathrm{h})$,

- the air wet-bulb temperature, $T_{w b}(t)\left({ }^{\circ} \mathrm{C}\right)$,

- the make-up water flow to the cooling towers, $f_{m u}(t)(\mathrm{t} / \mathrm{h})$, and

- the availability of the pumps, fans, and heat exchangers.

The variables to be regulated are

- the tempered water supply temperature, $T_{T W S}$,

- the tempered water differential temperature $\left(\Delta T_{T W}=T_{T W R}-T_{T W S}\right.$ where $T_{T W R}$ is the tempered return temperature), and

- the power consumption of the system $\left(W_{T}\right)$.

The steady-state model equations are given below (with reference to Figure 2 and Table 2). To add dynamics to the system, several of the variables are passed through first order filters with time constants as listed in Table 2 ([21], updated according tot the updated model). These include Equations 1, 2, 3, $10,11,12,13$ and 14 . 


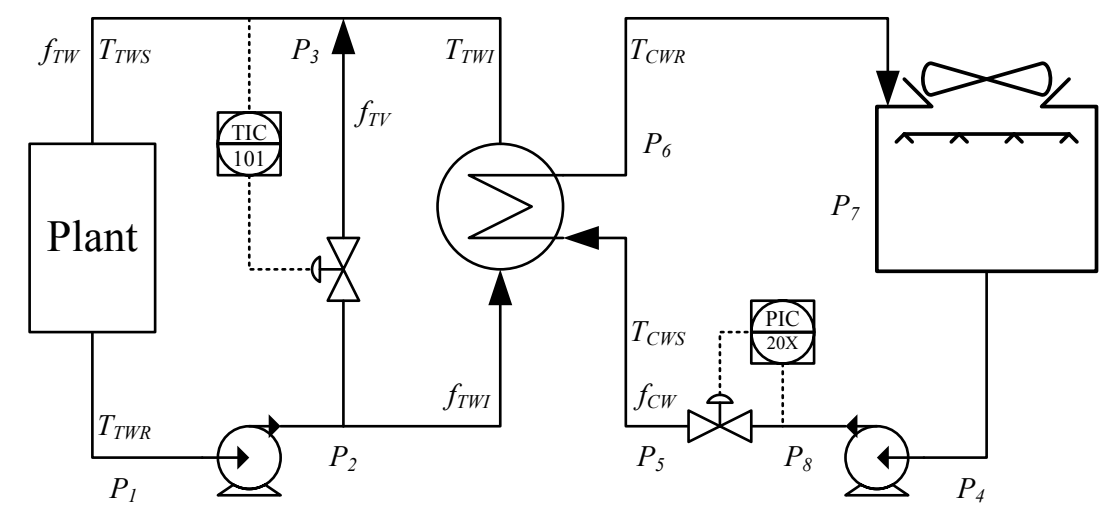

Figure 2: Simplified system representation [21].

Table 2: Model parameters.

\begin{tabular}{|c|l|l|l|}
\hline Variable & Description & Value & Units \\
\hline$\tau_{T V}^{f}$ & Temperature valve flow time constant & $1 / 60$ & $\mathrm{~h}$ \\
$\tau_{T W I}^{f}$ & Tempered water intermediate flow time constant & $1 / 60$ & $\mathrm{~h}$ \\
$\tau_{T W I}^{T}$ & Tempered water intermediate temperature time constant & $8.00 / 60$ & $\mathrm{~h}$ \\
$\tau_{T W S}^{T}$ & Tempered water supply temperature time constant & $6.06 / 60$ & $\mathrm{~h}$ \\
$\tau_{T W R}^{T}$ & Tempered water return temperature time constant & $21.42 / 60$ & $\mathrm{~h}$ \\
$\tau_{C W}^{f}$ & Cooling water flow time constant & $1 / 60$ & $\mathrm{~h}$ \\
$\tau_{C W S}^{T}$ & Cooling water supply temperature time constant & $7.39 / 60$ & $\mathrm{~h}$ \\
$\tau_{C W R}^{T}$ & Cooling water return temperature time constant & $4.38 / 60$ & $\mathrm{~h}$ \\
$P_{s}^{T W}$ & Tempered water pump suction pressure & 230 & $\mathrm{kPa}-\mathrm{g}$ \\
$P_{s}^{C W}$ & Cooling water pump suction pressure & 20 & $\mathrm{kPa}-\mathrm{g}$ \\
$K_{T W}$ & Tempered water pump head correction factor & 0.45 & - \\
$K_{C W}$ & Cooling water pump head correction factor & 0.32 & - \\
$\nu$ & Vapour fraction of cooling water flow & 0.00153 & $\% /{ }^{\circ} \mathrm{C}$ \\
$\alpha$ & Cooling tower approach value & 10 & ${ }^{\circ} \mathrm{C}$ \\
$\lambda$ & Water heat of vaporisation & 2260 & $\mathrm{~kJ} / \mathrm{kg}$ \\
$C_{p}$ & Water specific heat & 4.18 & $\mathrm{~kJ} / \mathrm{kg} .{ }^{\circ} \mathrm{C}$ \\
$C_{T V}$ & Temperature control valve flow coefficient & 912 & - \\
$C_{P V}$ & Pressure control valve flow coefficient & 136 & - \\
$C_{E T W}$ & Exchanger tempered water side flow coefficient & 737 & - \\
$C_{E C W}$ & Exchanger cooling water side flow coefficient & 539 & - \\
$C_{C T}$ & Single cooling tower flow coefficient & 193 & - \\
\hline
\end{tabular}




\begin{tabular}{|c|l|l|l|}
$C_{G}$ & Plant heat exchanger network flow coefficient & 812 & - \\
$R$ & Pressure control valve equal percentage coefficient & 50 & - \\
$\rho$ & Water specific gravity & 1 & $\mathrm{t} / \mathrm{m}^{3}$ \\
$g$ & Gravitational constant & 9.81 & $\mathrm{~m} / \mathrm{s}^{2}$ \\
$A$ & Heat exchanger area & 100 & $\mathrm{~m}^{2}$ \\
$U$ & Heat exchanger heat transfer coefficient & 284 & $\mathrm{MJ} / \mathrm{h} \cdot \mathrm{m}^{2} \cdot{ }^{\circ} \mathrm{C}$ \\
$W_{C T}^{\text {max }}$ & Cooling tower fan rated power & 150 & $\mathrm{~kW}$ \\
$c_{C}$ & Concentration cycles for cooling water circulation & 3 & - \\
$T_{a}$ & Ambient temperature & - & ${ }^{\circ} \mathrm{C}$ \\
$T_{w b}$ & Wet-bulb temperature & - & ${ }^{\circ} \mathrm{C}$ \\
$R H$ & Relative humidity & - & $\%$ \\
$Q_{P}$ & Plant duty & - & $\mathrm{MJ} / \mathrm{h}$ \\
$U_{C T}$ & Number of running cooling tower fans & - & - \\
$U_{C W}$ & Number of running cooling water pumps & - & - \\
$U_{T W}$ & Number of running tempered water pumps & - & - \\
$\left(O P_{T V}\right)$ & Pressure control valve opening & - & $\%$ \\
$\left(O P_{T V}\right)$ & Temperature control valve opening & - & $\mathrm{t} / \mathrm{h}$ \\
$T_{T W S}$ & Tempered water supply temperature & - & ${ }^{\circ} \mathrm{C}$ \\
$T_{T W R}$ & Tempered water return temperature & ${ }^{\circ} \mathrm{C}$ \\
$\Delta T_{T W}$ & Tempered water differential temperature & - & ${ }^{\circ} \mathrm{C}$ \\
$f_{m u}$ & Make-up water flow to the cooling towers & - & \\
$W_{T}$ & Power consumption of the system & - & \\
\hline
\end{tabular}

The flows $(\mathrm{t} / \mathrm{h})$ are calculated as

$$
\begin{aligned}
& f_{T V}=C_{T V} O P_{T V} \sqrt{\frac{\Delta P_{E T W}}{\rho}} \\
& f_{T W I}=C_{E T W} \sqrt{\frac{\Delta P_{E T W}}{\rho}} \\
& f_{C W}= \\
& \frac{C_{C T} U_{C T} C_{E C W} U_{C W} C V_{P V} R^{\left(O P_{P V}-1\right)} \sqrt{\Delta P_{C W P}}}{\sqrt{C_{E C W}^{2} U_{C W}^{2} C V_{P V}^{2} R^{2\left(O P_{P V}-1\right)}+C_{C T}^{2} U_{C T}^{2} U_{C W}^{2} C V_{P V}^{2} R^{2\left(O P_{P V}-1\right)}+C_{C T}^{2} U_{C T}^{2} C_{E C W}^{2}}}
\end{aligned}
$$


and

$$
f_{T W}=f_{T V}+f_{T W I}
$$

where $f_{T V}$ is the flow through the temperature control valve, $f_{T W I}$ is the intermediate flow through the tempered water side of the heat exchangers, $f_{C W}$ is the flow in the cooling water circuit and $f_{T W}$ is the total flow through the tempered water circuit. The constants are listed in Table 2. The differential pressures $(\mathrm{kPa})$ are calculated as

$$
\Delta P_{T W P}=k_{T W} h_{T W} \rho g
$$

$$
\Delta P_{C W P}=k_{C W} h_{C W} \rho g
$$

and

$$
\Delta P_{E T W}=\frac{\Delta P_{T W P}}{\left(\frac{C_{E T W}+C_{T V} O P_{T V}}{C_{G}}\right)^{2}+1}
$$

with

$$
h_{T W}=-\left(7 \times 10^{-6}\right)\left(\frac{f_{T W}}{U_{T W}}\right)^{2}+0.0036 \frac{f_{T W}}{U_{T W}}+88.28
$$

and

$$
h_{C W}=-\left(6 \times 10^{-6}\right)\left(\frac{f_{C W}}{U_{C W}}\right)^{2}+0.0005 \frac{f_{C W}}{U_{C W}}+58.30
$$

where $\Delta P_{T W P}$ is the differential pressure across the tempered water pumps, $\Delta P_{C W P}$ is the differential pressure across the cooling water pumps, $\Delta P_{C T}$ is the differential pressure across the cooling towers, $\Delta P_{E T W}$ is the differential 
pressure across the tempered water side of the heat exchangers (including the temperature valve), and $h_{C W}$ and $h_{T W}$ are the head calculations (in m) for the cooling water and tempered water pumps. With reference to Figure 2, $\Delta P_{E T W}=P_{2}-P_{3}, \Delta P_{T W P}=P_{2}-P_{1}$, and $\Delta P_{C W P}=P_{8}-P_{4}$. In addition, $\Delta P_{P}=P_{3}-P_{1}$ is the differential pressures across the plant, and $\Delta P_{P V}=P_{8}-P_{5}$ is the differential pressure across the cooling water pump discharge valves for the pumps that are in operation. The temperatures $\left({ }^{\circ} \mathrm{C}\right)$ are calculated as

$$
\begin{aligned}
& T_{T W S}=\frac{T_{T W I} f_{T W I}+T_{T W R} f_{T V}}{f_{T W}} \\
& T_{T W R}=\left(\frac{Q_{P}}{f_{T W} C_{p}}+T_{T W S}\right) \\
& T_{C W R}=\left(\frac{Q_{P}}{f_{C W} C_{p}}+T_{C W S}\right) \\
& T_{C W S}=\left(T_{C W R}-\frac{f_{e}}{f_{C W} \nu}\right)
\end{aligned}
$$

and

$$
T_{T W I}=\left(\frac{T_{C W S}-\frac{Q_{P}}{f_{T W I} C_{p}}-e^{K} T_{C W R}}{1-e^{K}}\right)
$$

with

$$
\begin{aligned}
K= & \left(\frac{Q_{P}}{f_{T W I} C_{p}}-T_{C W S}+T_{C W R}\right) \frac{U A}{Q_{P}} \\
T_{w b} & =T_{a} \tan ^{-1}\left(0.151977(R H+8.313659)^{0.5}\right) \\
& +\tan ^{-1}\left(T_{a}+R H\right)-\tan ^{-1}(R H-1.676331) \\
& +0.00391838\left(R H^{1.5}\right) \tan ^{-1}(0.023101 . R H) \\
& -4.686035
\end{aligned}
$$




$$
f_{e}=\left(\frac{c_{c}-1}{c_{c}}\right)\left(\frac{f_{m u}}{U_{C T}}-0.001\left(\frac{f_{C W}}{U_{C T}}\right)\right)\left(\frac{T_{C W S}}{T_{w b}+\alpha}\right) U_{C T}
$$

and

$$
Q_{e}=f_{e} \lambda
$$

where $T_{C W S}$ and $T_{C W R}$ are the cooling water supply and return temperatures, $T_{T W I}$ is the temperature of the water exiting the tempered water side of the heat exchangers, $T_{a}$ is the ambient air temperature, $R H$ is the relative humidity and $f_{e}$ is the estimated evaporative flow.

The total power $(\mathrm{kW})$ is calculated as

$$
W_{T}=W_{T W}+W_{C W}+W_{C T}
$$

where

$$
W_{T W}=U_{T W}\left(-\left(2 \times 10^{-5}\right)\left(\frac{f_{T W}}{U_{T W}}\right)^{2}+0.1772 \frac{f_{T W}}{U_{T W}}+131.7\right)
$$

is the power consumption of the TW pumps,

$W_{C W}=U_{C W}\left(-\left(8 \times 10^{-9}\right)\left(\frac{f_{C W}}{U_{C W}}\right)^{3}+\left(2 \times 10^{-5}\right)\left(\frac{f_{C W}}{U_{C W}}\right)^{2}+0.0195 \frac{f_{C W}}{U_{C W}}+182.9\right)$

is the power consumption of the CW pumps and

$$
W_{C T}=U_{C T} W_{C T}^{\max }
$$

that of the cooling tower fans. 


\section{Control Design}

By applying modern control techniques, the energy consumption of the system can be minimised while simultaneously maintaining the process within predetermined limits. Two cases are considered. The first is a base case to illustrate unoptimised operation. The second makes use of advanced regulatory control (ARC) techniques where specialised software is not required other than the plant's installed distributed control system (DCS) or programmable logic controller (PLC).

The process inputs (manipulated variables, MVs), disturbance variables $(\mathrm{DVs})$ and controlled variables $(\mathrm{CVs})$ are given in Section 3. The tempered water supply temperature $\left(T_{T W S}\right)$ and tempered water differential temperature $\left(\Delta T_{T W}\right)$ should be maintained within predefined limits whereas the power must be minimised. The constraints on the controlled variables are

- $26^{\circ} \mathrm{C} \leq T_{T W S} \leq 36^{\circ} \mathrm{C}$ and

- $\Delta T_{T W} \leq 6^{\circ} \mathrm{C}$.

Two simulation studies are presented. The first simulation covers a period of seven days using artificial data, during which step-like and ramp-like changes occur on the plant load and sinusoidal disturbances are introduced on the humidity and ambient temperature which affect the wet-bulb temperature (and therefore the cooling tower efficiency). The duty and wet-bulb temperature are shown in Figure 3.

For the second simulation, real plant data (as shown in Figure 4) was used as input data to illustrate the performance of the control schemes under a real plant operating scenario. The second simulation covers a period of 6 days (144 hours).

\subsection{Base Case}

As mentioned, a base case is established to represent the unoptimised operation. For the purposes of this study, the assumption is that one pump on 

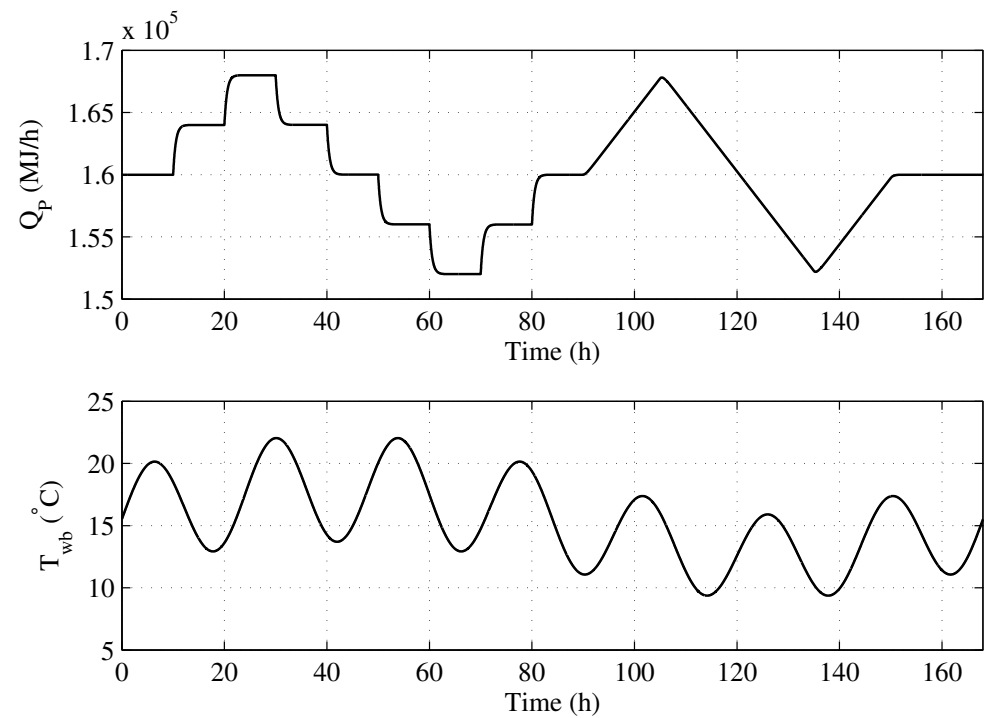

Figure 3: Model disturbance inputs for first simulation.

each bank and one cooling tower is used as a spare and therefore four pumps are running on each bank with three cooling towers. The only automatic control that is performed during this operation is the temperature controller that bypasses the heat exchangers (TIC-101). The cooling water pump discharge pressure controller valve openings (PIC-201 to 205 in Figures 1 and 2) are at $100 \%$ for the cooling water pumps that are running and zero for those that are not running. No switching is performed on the pumps and cooling towers. The resultant controlled variables are shown in Figure 5 and 6 which illustrate large constraint violations on $T_{T W S}$ and a high power consumption.

\subsection{Advanced Regulatory Control}

Advanced Regulatory Control (ARC) refers to a set of techniques that are implementable on most modern control systems without the need to purchase additional software or hardware but which go beyond the basic regulatory control provided by proportional integral derivative (PID) controllers. In the case of this study, these include cascade control, override selector control, and cus- 

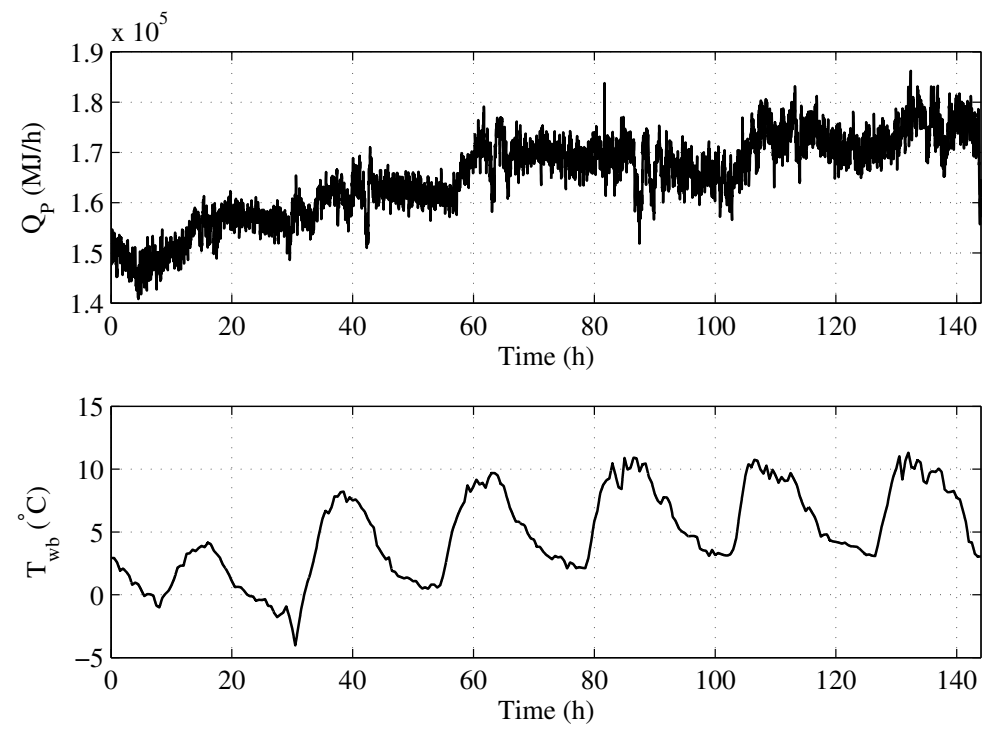

Figure 4: Model disturbance inputs for second simulation.

tom control algorithms $[25,26]$. The custom algorithms consist of condition and time based switching logic.

In comparison to the base case, some optimisation is performed and pumps and cooling towers are switched on/off depending on the operating conditions and equipment availability. The temperature controller on the tempered water side is still operated in the same automatic mode. The control scheme is shown in Figure 7. The control valves on the cooling water pump discharge lines are used for flow control (FIC-101) which replaces the pressure controllers (PIC-201 to 205). For constraint handling on the tempered water supply temperature, two temperature override controllers were added in a mid-of-three configuration to the flow controller setpoint, $f_{C W}^{S P}$, to allow the flow setpoint to deviate from the desired set value when the constraints are violated on either the low or high side. A reasonable desired flow setpoint was found to be $3000 \mathrm{t} / \mathrm{h}$.

The generic approach for the switching logic is as follows (with reference to the steps for control structure design as suggested in [25], [27], [28], [29] and [30]): 

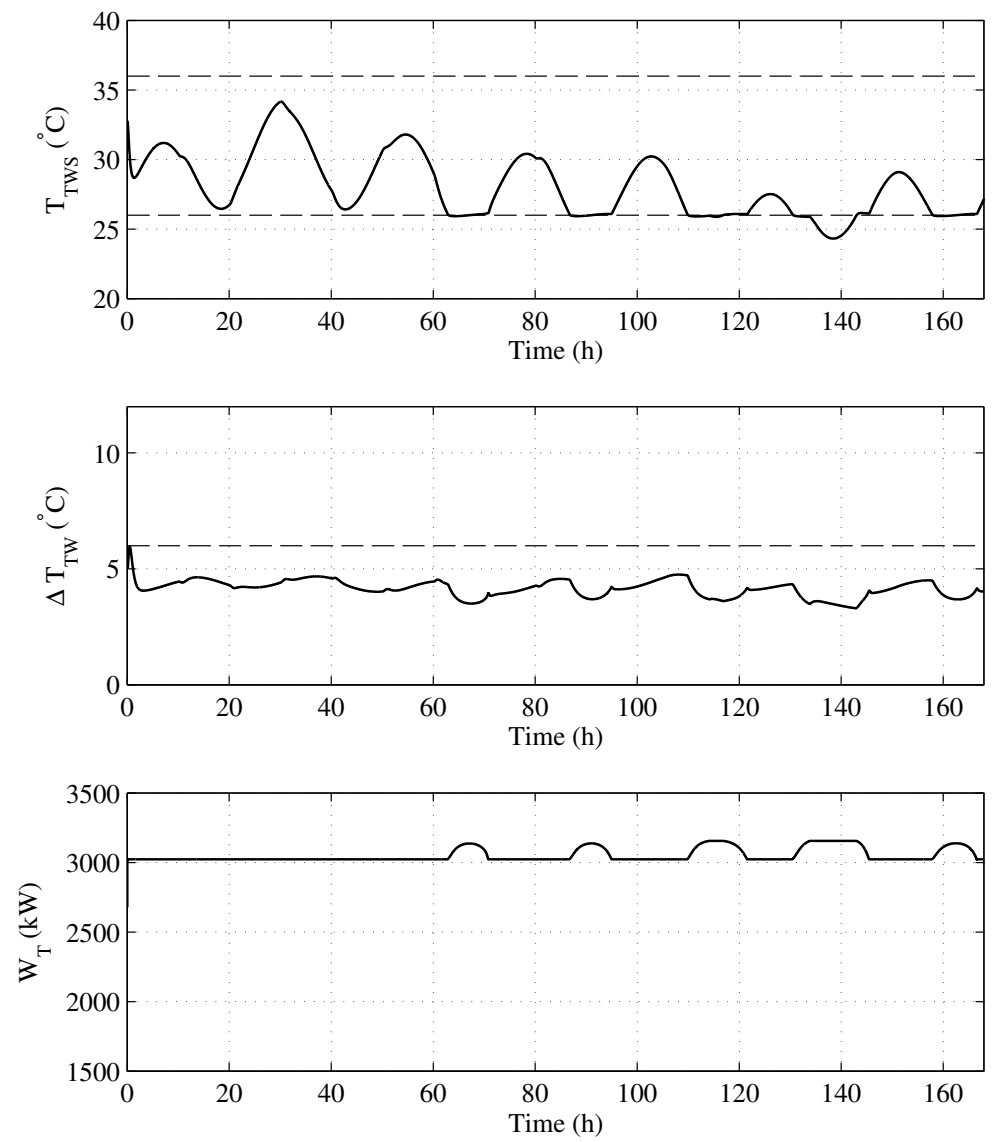

Figure 5: Controlled variables (base case - first simulation).

1. Specify the operational objective (the objective function).

2. Determine the controlled variables for the process (with the appropriate constraints).

3. Specify which discrete variables will be used in the switching logic.

4. Establish the effect of the discrete input variables on the controlled variables and the objective function.

5. Established the order of switching of the discrete input variables where more than one discrete variable affects a specific controlled variable.

6. Establish the limits on the discrete and continuous input variables (may 

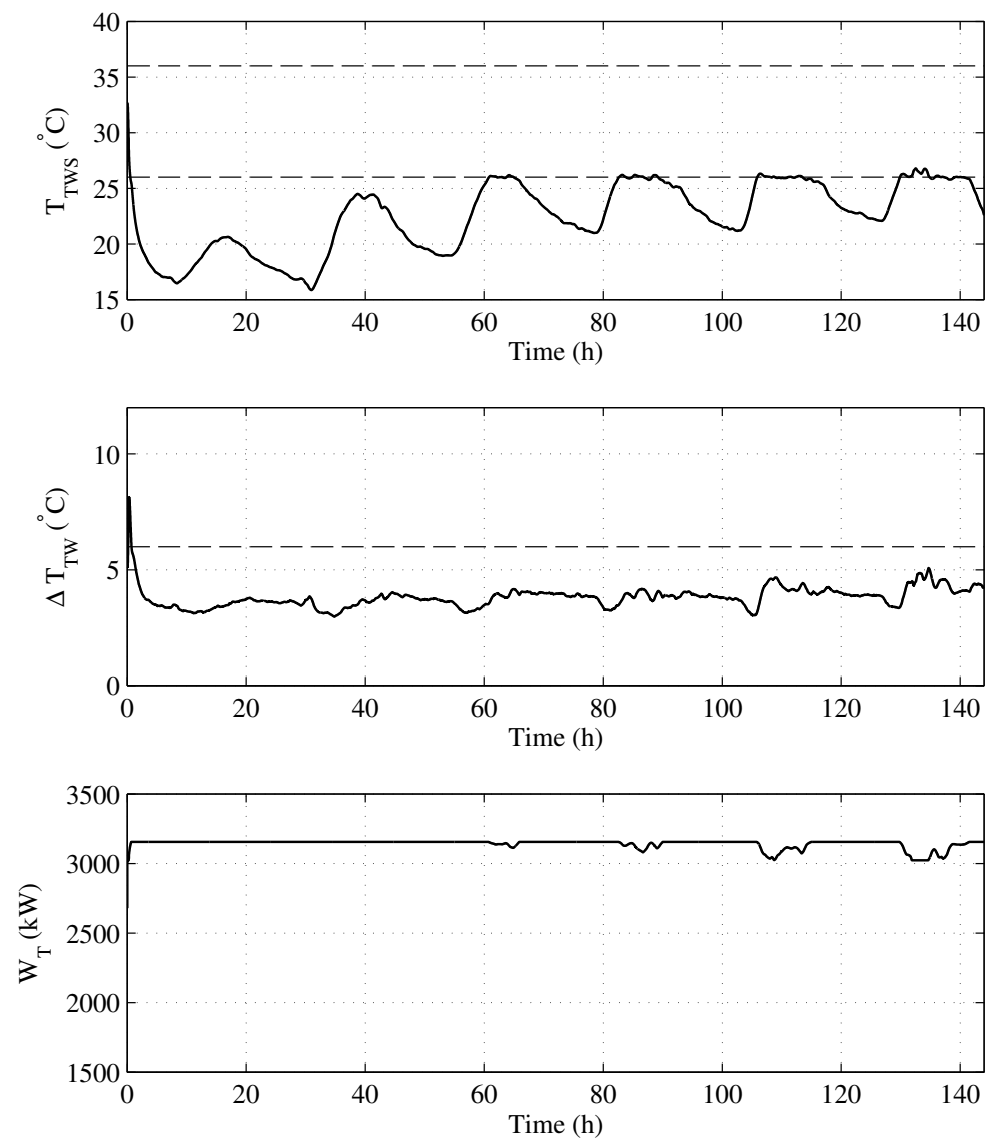

Figure 6: Controlled variables (base case - second simulation).

have to be re-evaluated regularly to account for changes in equipment availability).

7. Establish the default switching frequency (the time a condition must be active before a switching event will occur). Some conditions may require shorter delays or immediate switching.

8. Determine the dead-bands required for returning to range of the controlled variables to avoid chattering behaviour.

9. Formulate the rules for switching for each discrete variable based on the information gathered above. 


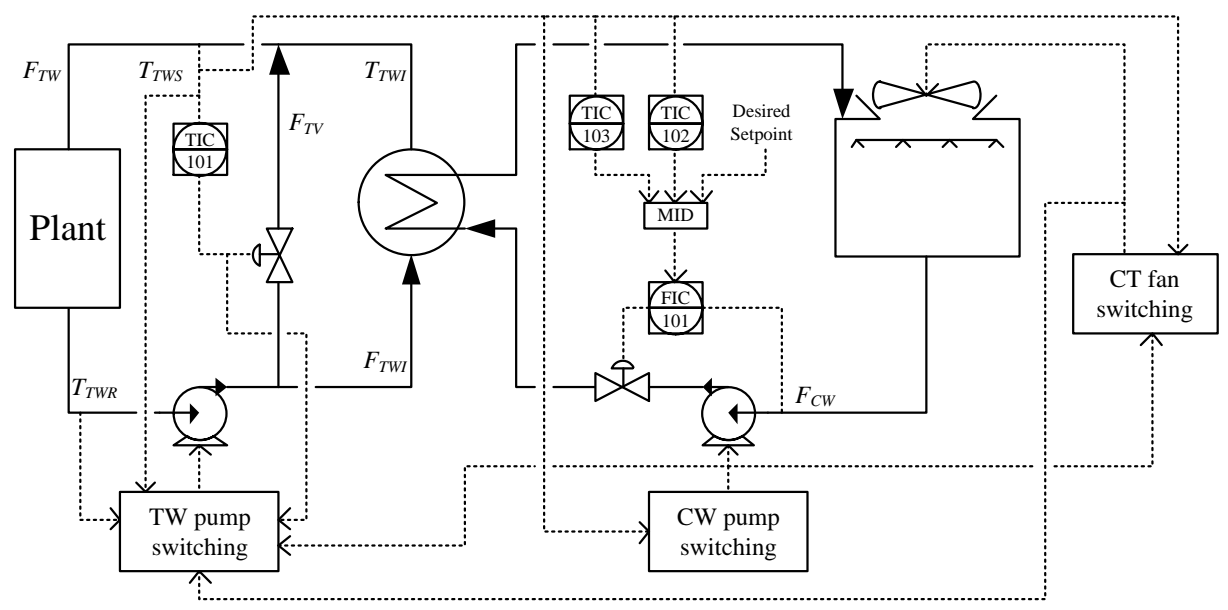

Figure 7: ARC scheme illustration.

In some cases the system may be simple such as a bank of fans used to control the pressure or temperature on a distillation column. In other cases the problem might be more involved and include multiple discrete variables and/or process variables (which is the case is this study).

Following this approach for the cooling water system, the conditions for the switching logic are as follows:

1. The objective is to minimise energy consumption (the objective function to be minimised is the total energy consumption).

2. The controlled variables for the process are $T_{T W S}$ and $\Delta T_{T W}$ with constraints as listed earlier.

3. All the discrete variables will be included in the switching logic $\left(U_{C W}\right.$, $U_{T W}$ and $\left.U_{C T}\right)$.

4. All of the discrete variables influence $T_{T W S}$, whereas only $U_{T W}$ has a substantial effect on $\Delta T_{T W}$. All the discrete variables affect the power consumption. The nature/direction of these effects can be determined from Section 3.

5. For $T_{T W S}$, the switching order is first $U_{C W}$, then $U_{C T}$ and lastly $U_{T W}$. 
This is based on the relative effectiveness of each of the discrete variables on manipulating the $T_{T W S}$.

6. The limits on the discrete variable values are $2 \leq U_{C W} \leq 5,2 \leq U_{T W} \leq 5$ and $1 \leq U_{C T} \leq 4$. The value of $O P_{T V}$ must remain below $95 \%$. In this case, changes in equipment availability are not taken into account.

7. If a condition is active for 30 minutes or more on any of the variables, a switching action will be initiated.

8. The dead-band for returning to range on $T_{T W S}$ is $2{ }^{\circ} \mathrm{C}$ and $1.75^{\circ} \mathrm{C}$ for $\Delta T_{T W}$.

The conditions for the switching logic grouped per discrete variable are then as follows:

- Cooling water pump switching:

- If $\left(T_{T W S} \leq 34\right)$ and $\left(U_{C W}>2\right)$ for more than 30 minutes, switch a cooling water pump off.

- If $\left(T_{T W S}>36\right)$ and $\left(U_{C W}<5\right)$ for more than 30 minutes, switch a cooling water pump on.

- Cooling tower fan switching:

- If $\left(T_{T W S}>36\right)$ and $\left(U_{C W}=5\right)$ and $\left(U_{C T}<4\right)$ for more than 30 minutes, switch a cooling tower fan on.

- If $\left(T_{T W S} \leq 34\right)$ and $\left(U_{C W}=2\right)$ and $\left(U_{C T}>1\right)$ for more than 30 minutes, switch a cooling tower fan off.

- Tempered water pump switching:

- If $\left(\Delta T_{T W}<4.25\right)$ and $\left(U_{T W}>2\right)$ and $\left(T_{T W S}>28\right)$ for more than 30 minutes, switch a tempered water pump off.

- If $\left(\Delta T_{T W} \geq 6\right)$ and $\left(U_{T W}<5\right)$ for more than 30 minutes, switch a tempered water pump on. 
- If $\left(T_{T W S} \leq 26\right)$ and $\left(U_{C W}=2\right)$ and $\left(U_{T W}<5\right)$ and $\left(O P_{T V} \geq 95 \%\right)$ for more than 30 minutes, switch a tempered water pump on.

Figures 8 and 9 show the MV and CV values for the ARC case for the first simulation with Figures 10 and 11 showing those for the second simulation.

\section{Simulation Results}

From Figures 5 and 6 it is clear that the base case exhibits several sustained constraint violations with no adjustment to the energy usage based on ambient conditions and plant load. Figures 8 and 10 show that the ARC results in a tremendous improvement in energy usage while still honouring constraints better than in the base case. The average power and total energy consumption values over the simulation periods for the two cases are shown in Table 3. All control is performed on the existing equipment without proposing any additional equipment such as variable speed drives (VSDs) which is often suggested as a requirement for energy optimisation on motorised equipment. Furthermore, no system model was used in the control algorithm.

Table 3: Average power and energy consumption comparison.

\begin{tabular}{llll}
\hline Case & $\begin{array}{l}\text { Average } \\
\text { Power }(\mathrm{kW})\end{array}$ & $\begin{array}{l}\text { Total } \\
(\mathrm{kWh})\end{array}$ & $\begin{array}{l}\text { energy } \\
\text { from base }\end{array}$ \\
\hline Simulation 1 & & & \\
\hline Base & 3,052 & 512,736 & - \\
ARC & 2,130 & 357,840 & $30.2 \%$ \\
\hline Simulation 2 & & & \\
\hline Base & 3,142 & 452,448 & - \\
ARC & 2,213 & 318,672 & $29.6 \%$ \\
\hline
\end{tabular}

Table 4 gives constraint violation indices for the tempered water supply temperature and differential temperature. This provides a means of comparing the relative abilities of the two schemes to maintain the controlled variables 

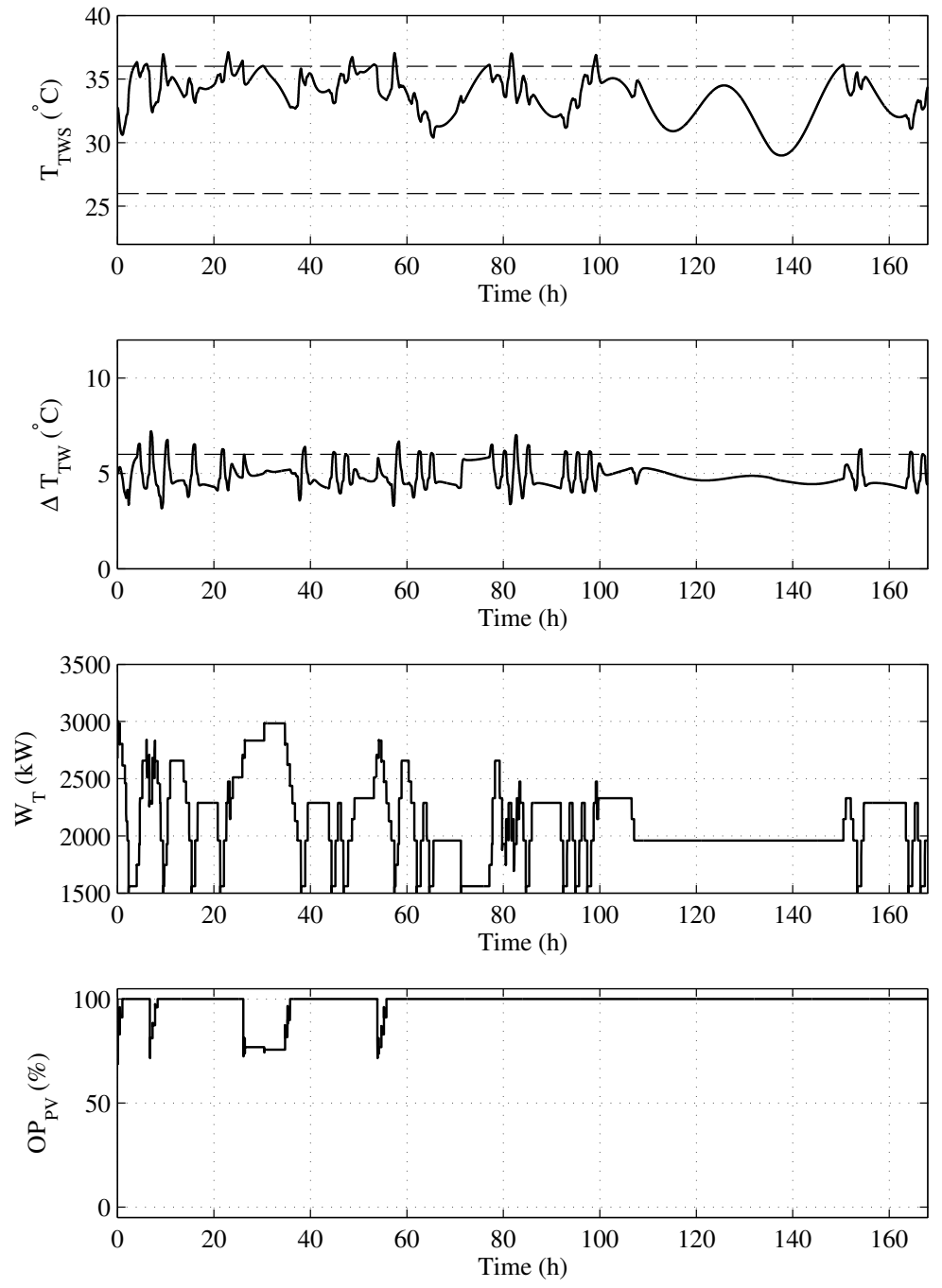

Figure 8: Controlled variables (ARC case - fist simulation). 

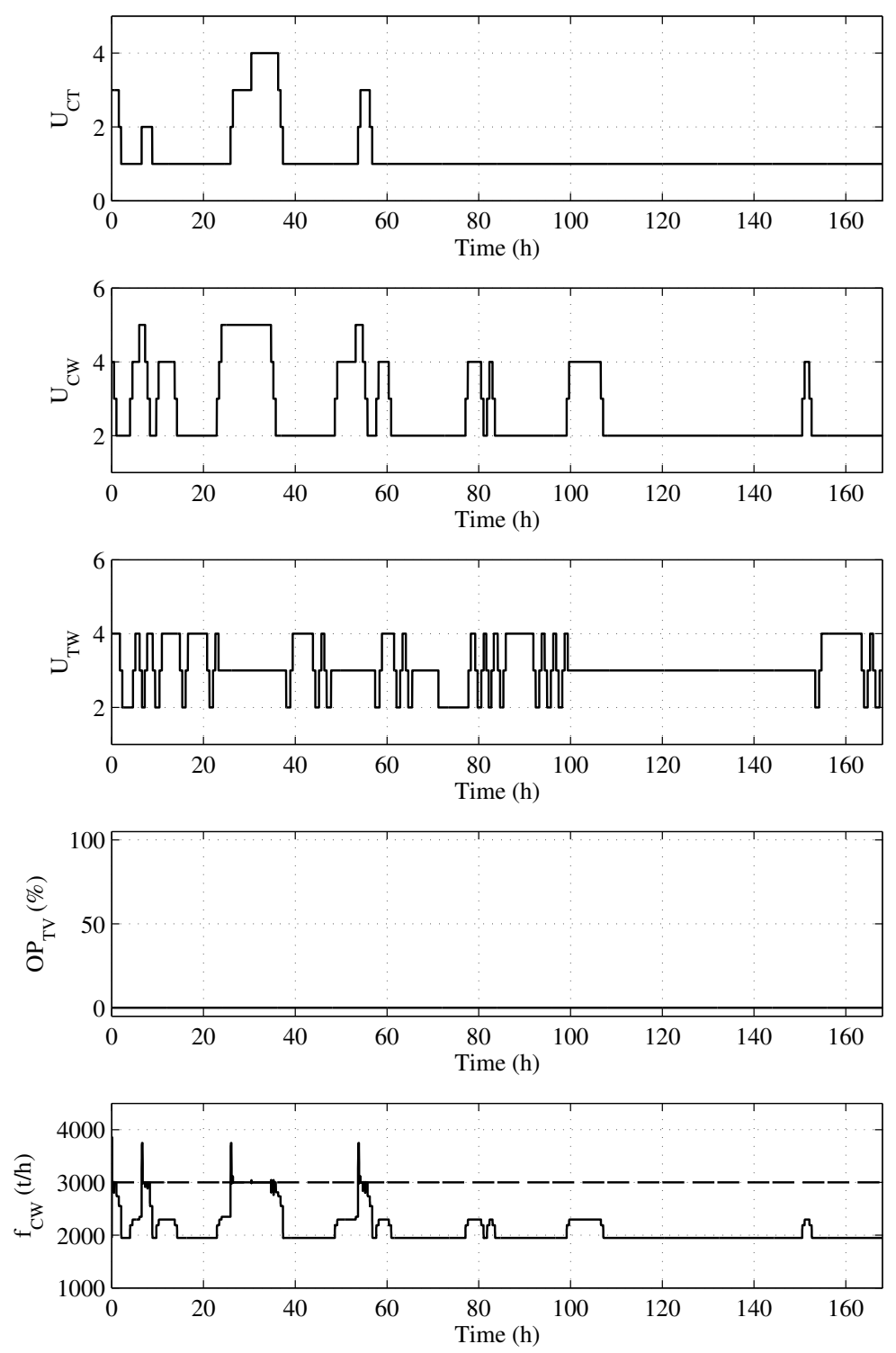

Figure 9: Manipulated variables (ARC case - first simulation). 

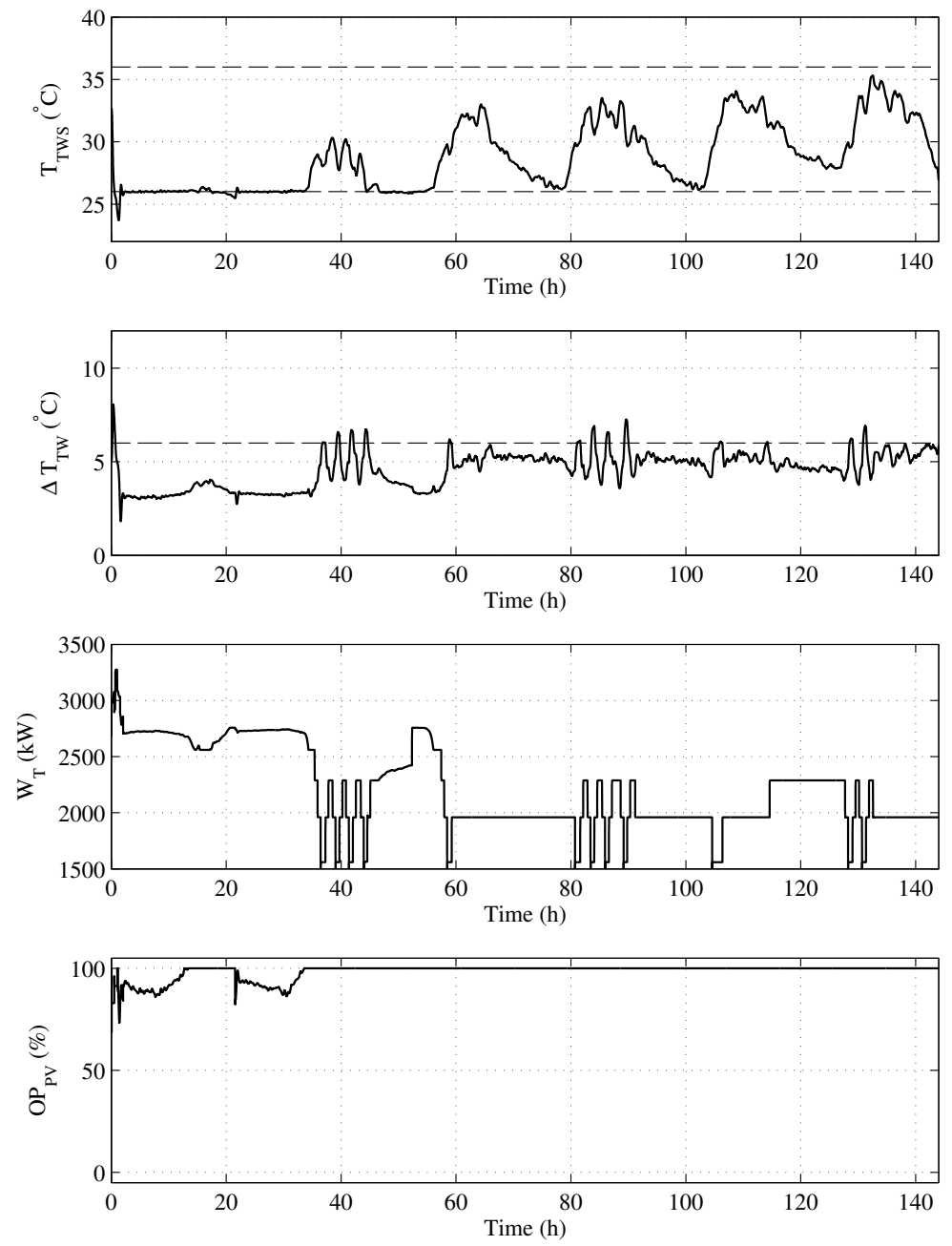

Figure 10: Controlled variables (ARC case - second simulation). 

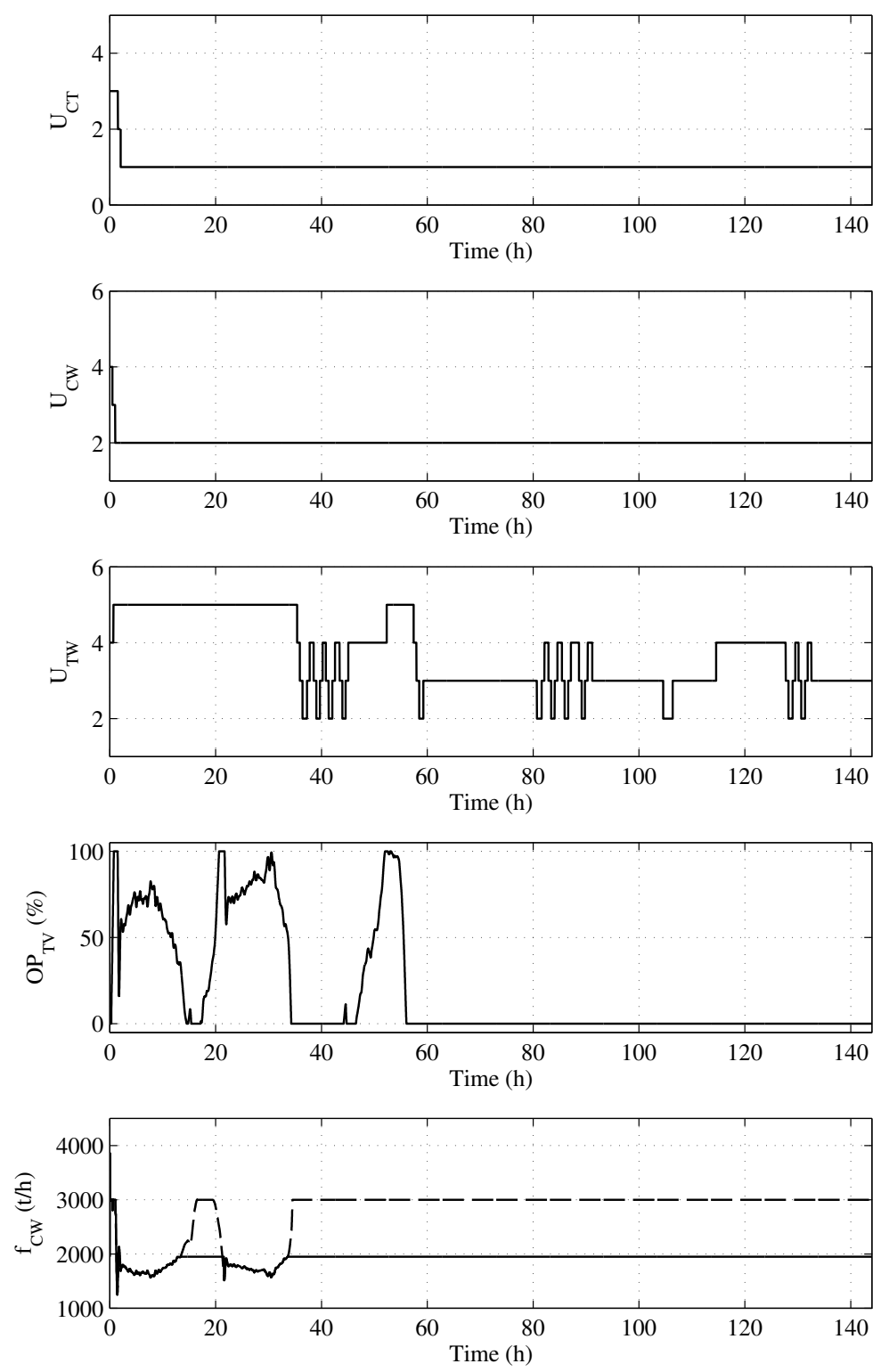

Figure 11: Manipulated variables (ARC case - second simulation). 
within the specified control limits. The violation of the limits on the main controlled variable (the tempered water supply temperature) is significantly improved with the implementation of the ARC techniques. The violation of the tempered water differential temperature constraint is slightly higher with the $\mathrm{ARC}$ as a result of the optimisation pushing towards the upper limit though the violation is still acceptable.

Table 4: Constraint violation comparison.

\begin{tabular}{lll}
\hline Case & $e_{T_{T W S}}$ & $e_{\Delta T_{T W}}$ \\
\hline Simulation 1 & & \\
\hline Base & 0.0691 & 0.0000 \\
ARC & 0.0207 & 0.0208 \\
\hline Simulation 2 & & \\
\hline Base & 3.5254 & 0.0047 \\
ARC & 0.0190 & 0.0244 \\
\hline
\end{tabular}

\section{Conclusion}

Utility generation and transmission are often overlooked as optimisation areas although the potential for energy reduction could be substantial in some cases. As illustrated in this paper, the application of advanced regulatory control techniques can be very effective optimisation vehicles for this purpose and a wealth of knowledge exists in this field. These techniques also cater for hybrid systems that contain continuous as well as discrete components and do not require a plant model to be developed. Furthermore, a large benefit may be obtainable by using the existing plant control system with the existing equipment without the need to purchase specialised control software or install additional equipment such as VSDs. This improves the likelihood of getting a solution like this approved and implemented on a plant. If further improvement is required, other advanced process control (APC) techniques may be considered (still without the need for VSDs). 


\section{References}

[1] B. G. Lipták, Distillation Control \& Optimization, Putman Media, 2007.

[2] R. Inglesi-Lotz, J. N. Blignaut, South Africa's electricity consumption: A sectoral decomposition analysis, Applied Energy 88 (12) (2011) 4779-4784.

[3] R. Saidur, N. A. Rahim, M. Hasanuzzaman, A review on compressed-air energy use and energy savings, Renewable and Sustainable Energy Reviews 14 (4) (2010) 1135-1153.

[4] M. S. Bhatt, Energy audit case studies I-steam systems, Applied Thermal Engineering 20 (3) (2000) 285-296.

[5] C. J. Muller, I. K. Craig, N. L. Ricker, Modelling, validation, and control of an industrial fuel gas blending system, Journal of Process Control 21 (6) (2011) 852-860.

[6] N. L. Ricker, C. J. Muller, I. K. Craig, Fuel gas blending benchmark for economic performance evaluation of advanced control and state estimation, Journal of Process Control 22 (6) (2012) 968-974.

[7] J. Palm, P. Thollander, An interdisciplinary perspective on industrial energy efficiency, Applied Energy 87 (10) (2010) 3255-3261.

[8] Z. Wu, H. Tazvinga, X. Xia, Demand side management of photovoltaicbattery hybrid system, Applied Energy 148 (2015) 294-304.

[9] J. Široký, F. Oldewurtel, J. Cigler, S. Prívara, Experimental analysis of model predictive control for an energy efficient building heating system, Applied Energy 88 (9) (2011) 3079-3087.

[10] K. C. Edwards, D. P. Finn, Generalised water flow rate control strategy for optimal part load operation of ground source heat pump systems, Applied Energy 150 (2015) 50-60. 
[11] S. Zhang, X. Xia, Optimal control of operation efficiency of belt conveyor systems, Applied Energy 87 (6) (2010) 1929-1937.

[12] B. Matthews, I. K. Craig, Demand side management of a run-of-mine ore milling circuit, Control Engineering Practice 21 (6) (2013) 759-768.

[13] S. Zhang, X. Xia, Modeling and energy efficiency optimization of belt conveyors, Applied Energy 88 (9) (2011) 3061-3071.

[14] A. Middelberg, J. Zhang, X. Xia, An optimal control model for load shifting with application in the energy management of a colliery, Applied Energy $86(7-8)(2009)$ 1266-1273.

[15] A. J. van Staden, J. Zhang, X. Xia, A model predictive control strategy for load shifting in a water pumping scheme with maximum demand charges, Applied Energy 88 (12) (2011) 4785-4794.

[16] X. Zhuan, X. Xia, Optimal operation scheduling of a pumping station with multiple pumps, Applied Energy 104 (2013) 250-257.

[17] Y. Wang, Q. Chen, A direct optimal control strategy of variable speed pumps in heat exchanger networks and experimental validations, Energy 85 (1) (2015) 609-619.

[18] H. Zhang, X. Xia, J. Zhang, Optimal sizing and operation of pumping systems to achieve energy efficiency and load shifting, Electric Power Systems Research 86 (2012) 41-50.

[19] A. Bemporad, M. Morari, Control of systems integrating logic, dynamics, and constraints, Automatica 35 (3) (1999) 407-427.

[20] E. F. Camacho, D. R. Ramirez, D. Limon, D. Muñoz de la Peña, T. Alamo, Model predictive control techniques for hybrid systems, Annual Reviews in Control 34 (1) (2010) 21-31. 
[21] C. J. Muller, I. K. Craig, Modelling of a dual circuit induced draft cooling water system for control and optimsation purposes, Journal of Process Control 25 (2015) 105-114.

[22] D. W. Green (Ed.), Perry's Chemical Engineers' Handbook, 4th Edition, McGraw-Hill, 1997.

[23] B. G. Lipták, Instrument Engineers' Handbook, 4th Edition, Vol. II: Process Control and Optimization, CRC Press, Florida, 2006.

[24] D. Q. Mayne, Model predictive control: Recent developments and future promise, Automatica 50 (12) (2014) 2967-2986.

[25] D. E. Seborg, T. F. Edgar, D. A. Mellichamp, Process Dynamics and Control, 2nd Edition, Wiley, 2004.

[26] H. L. Wade, Regulatory and Advanced Regulatory Control: System Development, ISA, 1994.

[27] S. Skogestad, I. Postlethwaite, Multivariable Feedback Control Analysis and Design, 2nd Edition, Wiley, 2005.

[28] S. Skogestad, Control structure design for complete chemical plants, Computers and Chemical Engineering 28 (1-2) (2004) 219-234.

[29] T. Larsson, S. Skogestad, Plantwide control - a review and a new design procedure, Modeling, Identification and Control 21 (4) (2000) 209-240.

[30] J. J. Downs, S. Skogestad, An industrial and academic perspective on plantwide control, Annual Reviews in Control 35 (1) (2011) 99-110. 